\title{
Using quinoa protein and starch nano particles to produce edible films
}

\begin{abstract}
The aim of the study is to from quinoa protein and starch nano particles produce edible natural films from quinoa protein and starch nano particles. Rheological properties of edible solution and suspensions were studied. Rheological, mechanical properties, permeability, partical size distribution, zeta potentioal emulsion, X-R diffraction(XRD) films as well as the scanning electron microscopy of the films were evaluated. The results of the study film-forming quinoa protein and starch nanoparticles with the incorporation of $(0.5 / 4.5 \%)$ of crude phenolic compounds extracts (as antioxidants) luria leaves or pomegranate Peels/acetic acid glacial. Tests and measurements showed that the best film-forming nano suspensions were in decreasing order $\mathrm{B}(55.61 \mathrm{~nm})$, $\mathrm{E}(68.66 \mathrm{~nm})$ then followed treatment $\mathrm{F}(73.51 \mathrm{~nm})$ and $\mathrm{C}(84.13 \mathrm{~nm})$ Compared to noncarrying natural films (as antioxidants) were $\mathrm{D}(156.8 \mathrm{~nm})$ and $\mathrm{A}(280.9 \mathrm{~nm})$. These protein and starch nano particles are able to form films and coatings with good barrier properties against the transport of gases such as oxygen, carbon dioxide and water vapors. On the other hand, the thickness, tensile strength, elongation, present solubility is important mechanical properties where they increased in strength with treatment nanoparticles. This technology will also enable the development of new edible natural films materials to extend the shelf life of food. Nanoparticles have the ability to provide a safe packaging system and its new technological applications in the production of edible natural films to inhibit microbial growth, reduce oxidation and food-borne preservation, increase the economic feasibility and benefit of quinoa seeds since these seeds are not commercially used and are not used for their high content of saponine.
\end{abstract}

Keywords: edible films, mechanical properties, partical size distribution, zeta potentioal emulsion, X-R diffraction(XRD) films, scanning electron microscopy films
Volume 8 Issue 4 - 2018

\author{
Hosam El Din Aboul-Anean \\ Food Engineering and Packaging Department, Food Technology \\ Research Institute, Egypt
}

\author{
Correspondence: Hosam El din Aboul anean, Food \\ Engineering and Packaging Dept.Food Tech. Res. Institute, \\ Agricultural Research Center, Giza, Egypt, Email hosam.ftri@ \\ yahoo.com
}

Received: July 10, 2018 | Published: August 22, 2018

\section{Introduction}

Quinoa seeds have been traditionally consumed asfunctional food high nutritional value and its bitter taste. The coat of quinoa seeds has been only characterized in terms of its high triterpene saponin content. Thus, quinoa saponins promote hemolysis and changes in intestinal permeability. Thus, that the quinoa coat, the outmost layer of the seed, contains antioxidants. ${ }^{1}$ Quinoa has been selected by (FAO 2014) as one of the crops destined to offer food security in the 21 st century, because the quinoa plants are tolerant to salinity and drought stress, and can grow on marginal regions. Quinoa seeds have a high protein content (about 15\%), and its essential amino acid balance is excellent, because of a wider amino acid spectrum than cereals and legumes. ${ }^{2}$ Quinoa is one of the most nutritive grains used as human food, and FAO has selected it as one of the crops destined to offer food security in this century. ${ }^{3}$ The digestibility of quinoa protein is the limiting factor in the protein utilization in food. In vitro digestibility of quinoa protein varied from $76.3 \%$ to $80.5 \%{ }^{4}$ Edible coatings applied on fresh fruits was to reduce the moisture transfer, oxidation, metabolic processes, respiration rate, physical/mechanical impacts and microbial growth and to maintain the sensory quality and safety to prolong their shelf-life. Edible coating actsas a physical barrier for the gas exchange between the fruit and their storage environment to create modified atmosphere, it slows down both the rates of generating energy and substrate degradation which inturn will slow down the biochemical reactions leading to fruit ripening. The polysaccharides, as coating materials forfruits have been used extensively in the past fewyears. These natural polymers, in addition to theabove mentioned benefits, present advantages due totheir availability, low cost, and biodegradability. The latter in particular is of great interest, as it leads to a reduction in the large quantities of non-biodegradable synthetic packaging materials. In addition, their physico-chemical properties can also be improved by modifying them. ${ }^{5}$

Although the addition of oil to the film decreased the WVP, an adverse effect on the mechanical properties of the film was observed compared with films without oil. In addition, interactions with lipids and/or proteins diminish or inhibit the antimicrobial activity (AM) of chitosan and a blend of chitosan/quinoa-protein, increasing interest in the incorporation of additional powerful as antimicrobial agents. Thymol, which is found in the essential oil of thyme, exhibits potent as antimicrobial effects against various microbial strains and is considered a safe food additive by the FDA. Nano composites can improve the water vapour barrier properties of hydrophilic films without affecting their mechanical properties. Nanoparticles (NPs) located in the domains of the links between the film-forming polymers hinder the diffusion of gases and water molecules through the film and create a diffusive tortuosity effect on the transport of molecules through the film. ${ }^{6}$ Protein-based particles are most readily generated by thermal processing. When heated above their denaturation temperature, globular proteins exhibit unfolding of their polypeptide chains followed by the intermolecular association under the influence 
of hydrophobic and covalent bonding. The morphology and microstructure of the resulting aggregates are found to be sensitively dependent on the aqueous solution environment and on the processing conditions temperature, time, shear-rate. Adjustments in conditions, can influence the delicate balance of intermolecular forces and hence the rates of competing chemical reactions. Consequently, particular protein a broad range of morphologies may be produced. ${ }^{7}$

The $\mathrm{pH}$ range required for the preparation of spherical particles from protein of uniform size $(\sim 200 \mathrm{~nm})$ being formed above or below the optimum $\mathrm{pH}(\sim 6)$. The protein charge density must be sufficiently low to allow microgel formation, but high enough to inhibit further protein association into large clusters or macroscopic gels. ${ }^{8}$ Nanoscale starch particles are novel materials which present unusual chemical properties due to their extremely small size and wide surface area. They have a number of advantages over bulk starch, such as high surface area per unit of mass, and high absorption capacity, and minimal diffusional limitations. Nano-scalestarch particles have attracted considerable research interest due to their excellent properties and have been prepared through different methods, such as combining complex formation acid hydrolysis and regeneration. The dispersibility of the nano-scale starch particlesin aqueous solution is reflected by the rheological properties, which are important for their applications both when they are used alone and when they are part of a mixture. In the food industry, thermal process designs for liquids require accurate information on their flow behavior in order to develop processing conditions that ensure safety and product quality. ${ }^{9}$ The rheological properties modeled those of a continuous treatment process, as the flow characteristics of pumpable liquids dependent on the liquids viscosity and density, and thus play a major role in such processes. Hence, the detected rheological properties of suspensions containing the novel nanoparticles the viscosity of nanoparticle suspensions has the potential to influence the delivery of active components and the performance of films and improvement the rheological properties of Nano starch particles. ${ }^{10}$

Starch hydrolysis by hydrochloric or sulphuric acid at subgelatinization temperatures causes a preferential attack of acid molecules in the amorphous regions of the granule. These particles may be used in widespread biomedical, biochemical and technological applications, as well as vehicles for carrying bioactive substances and nutraceuticals. Starch nanocrystals however tend to aggregate and settle down in aqueous solutions which limits their application in food system. ${ }^{11}$ Pomegranate peels are considered inedible parts or byproduct obtained through juice processing it is characterized by significant presence of ellagitannins and polyphenols, gallic acid and ellagic acid as well as flavonoids -associated with biological properties such as antioxidant and antimicrobial agents. As antioxidant activity of extracts of pomegranate peels. Pomegranate juice manufacturing industries generate large amounts of byproducts leading to serious environmental pollution in addition to acting as a substrate for the proliferation of insects and microorganisms. ${ }^{12}$ Recovery of antioxidant compounds from plant materials is typically accomplished through different extraction techniques taking into account their chemistry and uneven distribution in the plant matrix. For example, soluble phenolics are present in higher concentrations in the outer tissues (epidermal and sub-epidermal layers) of fruits and grains than in the inner tissues. Solvent extraction is most frequently used technique for isolation of plant antioxidant compounds. However, the extract yields and resulting antioxidant activities of the plant materials are strongly dependent on the nature of extracting solvent, due to the presence of different antioxidant compounds of varied chemical characteristics and polarities that may or may not be soluble in a particular solvent. Polar solvents are frequently employed for the recovery of polyphenols from a plant matrix..$^{13}$ The objective of this work is extraction quinoa protein and starch nano particles to produce edible natural films. And study rheological, mechanical properties, permeability, particle size distribution, zeta potential emulsion, X-R diffraction(XRD) films and scanning electron microscopy to select the best edible nature films estimated by the previous tests.

\section{Materials and methods}

\section{Materials}

Quinoa seeds (genotypes KVL-SRA2) were obtained in winter seasons of 2015/2016 at Agricultural Experimental Station of Desert Research Center, Cairo, Egypt. The seeds were cleaned from impurities and foreign materials, and then stored in a dry place at room temperature $\left(25 \pm 2^{\circ} \mathrm{C}\right)$ for future extraction. Luria leaves and pomegranate peels were obtained from the local market. At Central Lab of Agriculture Res. Food Engineering and Packaging Dept., Food Technology Research Institute, Agricultural Research Center, Giza, Egypt to study the preparation of quinoa protein and starch extract nano particles to produce edible natural films. The materials used in this experiment were: Ethyl alcohol 95\%, Chloroform and Methanol produced by were obtained from (El Nasr Pharmaceutical chemicals company, Cairo, Egypt). Sulfuric acid" $\mathrm{H}_{2} \mathrm{SO}_{4}$ "and Hydrochloric acid "HCL" were obtained from (El-Gomhouria chemical company. Glycerol and sodium hydroxide was obtained from (Acmatic For Chemicals \& Lab. Equipment Company, Cairo, Egypt). Acetic acid glacial was obtained from (Across Organics, Belgium). Whatman No.1 filter paper and decanter 50 mesh was obtained from acrossorganics Company New Jersey U.S.A. Glutaraldehyde was obtained from Win Lab Company, (U.K). Tween 80 from Zhejiang Sliver elephant Bio-Engineering Co., LTD, China. Sodium chloride " $\mathrm{NaCl}$ " was obtained from Jenapharm, Germany.

\section{Methods}

Preparation of quinoa flour: Quinoa flour was prepared according to Margarita et al., ${ }^{14}$ Quinoa seed were washed with cold water 4-5 times or until there was no foam to remove saponins drying was carried out at $50^{\circ} \mathrm{C}$ using a convective dryer and ground using a cyclone sample mill into meal that could pass through a 60-80 mesh screen.

\section{Preparation of quinoa protein extract nano particles:}

Extraction of quinoa protein: The obtained flour was defatted three times with chloroform: methanol (2:1), 1:10 w/v(flour/solvent) with shaking for $2 \mathrm{~h}$ to remove lipids from the sample. Quinoa protein isolate was prepared according to Elsohaimy et al., ${ }^{4}$ Fifty grams of defatted quinoa flour were suspended in $1000 \mathrm{ml}$ deionized distilled water $(1: 20 \mathrm{v} / \mathrm{v})$, and the $\mathrm{pH}$ was adjusted to 10 using $0.1 \mathrm{~N} \mathrm{NaOH}$ and $0.1 \mathrm{~N}$ $\mathrm{HCl}$. The suspension was stirred for $1 \mathrm{~h}$ with maintaining the $\mathrm{pH}$ at the determined value to reach the maximum level of solubilization. Then the suspension was filtered through nylon cloth with hydraulically pressed at 40psi to separate the suspended the solution from the fibers residue, adjusting the $\mathrm{pH}$ of these suspensions to 4.5 (the average isoelectric point). The mixture was centrifuged at $6000 \mathrm{xg}$ at $20^{\circ} \mathrm{C}$ for $30 \mathrm{~min}$ by high-speed centrifuge to obtain precipitates with relatively high percentages of protein. The precipitated protein product was dried in an air dryer at $50^{\circ} \mathrm{C}$ followed by grinding into powder. 
Preparation of quinoa protein nano particles fabrication: Desolvating agent (ethanol) was added drop wise into the dispersion the concentrations of Protein quinoa and ethanol after mixing ranged from $4 \sim 12 \mathrm{mg} / \mathrm{mL}$ and $0 \sim 80 \%$, respectively. After $15 \mathrm{~min}$ of equilibration, glutaraldehyde $(25 \mathrm{mg} / \mathrm{mL}$ aqueous solution) was added as a cross linked and it also reduces the average molecular weight, gave the amount of glutaraldehyde required for stoichiometric cross linking. ${ }^{15}$ Desolvation technique was employed for preparation of Protein quinoa nano particles. At first, Protein quinoa powder at concentrations of 1.5 to $4 \mathrm{mg} / \mathrm{mL}$ was dissolved in deionized water and its $\mathrm{pH}$ was adjusted to 9.0 with 0.1 and $1.0 \mathrm{M} \mathrm{NaOH}$ solution during stirring. The influence of Protein quinoa concentration on the size of prepared nano particles was filtered Protein quinoa solution was subjected to levels of $100 \%$ sonication method. Nano particles were obtained by dropwise non-solvent addition to Protein quinoa aqueous solution under constant stirring until the solution became turbid. Ethanol or acetone was applied as desolvating agents, desolvation method was accomplished by sonication technique $(400 \mathrm{~Hz}, 10 \mathrm{~min}$, $25 \pm 5 \mathrm{C})$. After the desolvation process, glutaraldehyde $(8 \% \mathrm{~V} / \mathrm{V}$ in water) was added to induce particle cross linking. The cross linking process was performed under stirring of the suspension over a time period of $24 \mathrm{~h}$. The purpose of adding of glutaraldehyde achieve a higher reaction rate of Protein quinoa as a good enhanced due to use of tween- 80 was added to block the non-reacted aldehyde functional group and stabilize the preparation. ${ }^{16}$ Large aggregates were eliminated by centrifuge at $6,000 \mathrm{rpm}$ for $20 \mathrm{~min} .{ }^{17,18}$ The particle size and size distribution of Protein quinoa nanoparticles. ${ }^{19}$ The percentage of protein in the supernatant was higher than $95 \%$ to remove ethanol, which was then replaced with same volume of deionized water. The resultant dispersion, containing less than 10\% ethanol, was centrifuged at $6,000 \mathrm{~g}$ for $20 \mathrm{~min}$ to remove large aggregates. The percentage of protein in the supernatant was higher than $95 \%$. The film forming solutions of $20 \mathrm{~g}$ were cast on plate. These were dried at $50 \pm 1^{\circ} \mathrm{C}$ for $24 \mathrm{~h}$

\section{Preparation of quinoa starch extract nanoparticles}

Extraction of quinoa starch: Quinoa grains $(1 \mathrm{~kg})$ were first washed at least four times in an excess of deionized water in order to remove the saponins which are totally soluble in water. The seeds were then steeped in deionized water at $3^{\circ} \mathrm{C}(1 \mathrm{~kg}$ seed $/ 2 \mathrm{~L}$ deionized water $)$ for $8 \mathrm{~h}$. The softened grain suspension was then milled in a kitchen blender and the resulting slurry screened and washed through a series of sieves $(80,200$ and 270 mesh) with deionized water. The sievingwashing procedure was repeated five times until there was no further starch-like color associated with the material retained on the sieves. The spent material retained on the sieves then being discarded. The material that passed through the sieves was centrifuged $(600 \mathrm{~g}, 20 \mathrm{~min}$, $4^{\circ} \mathrm{C}$ ), and the upper layer containing the protein and fine fiber found on top of the sediment, was removed. The remaining starch cake was resuspended in deionized water, centrifuged, and the dark upper layer removed, repeating this process five times. The starch collected at the end of this process was suspended in aqueous $0.20 \%(\mathrm{w} / \mathrm{w}) \mathrm{NaOH}$ at an alkaline $\mathrm{pH}$ value of 10.5 , and gently stirred for $5 \mathrm{~min}$ at $15^{\circ} \mathrm{C}$ to avoid any rise in temperature during this process. The suspension was then centrifuged, resuspended in deionized water and neutralized carefully $\mathrm{pH} 7$ by adding $0.1 \mathrm{M} \mathrm{HCl}$. After centrifugation, the starch cake was resuspended in deionized water, centrifuged and removed (five times) in order to remove any traces of the mucilage layer (residual protein material) in the upper layer and any ionic components of the $\mathrm{NaCl}$ resulting from the neutralization process. Dehydrated in an air dryer at $50{ }^{\circ} \mathrm{C}$ followed bygrinding brown into fine powder. ${ }^{20}$
Preparation of quinoa starch nano particles: The preparation of quinoa starch nanocrystals by sulfuric acid $\left(\mathrm{H}_{2} \mathrm{SO}_{4}\right)$ hydrolysis of native quinoa starch. Briefly, $36.725 \mathrm{~g}$ of native quinoa starch granules was mixed with $250 \mathrm{ml}$ of $3.16 \mathrm{M}\left(\mathrm{H}_{2} \mathrm{SO}_{4}\right)$ for 5 days at $40^{\circ} \mathrm{C}$ with a stirring speed of 100rpm. The suspension was washed by successive centrifugations with distilled water until achieving neutrality and then dried at $50 \pm 1{ }^{\circ} \mathrm{C}$ dried to obtain the starch nanocrystals. Starch nano particles were prepared using the method described by Sun et al., ${ }^{21}$ with some modifications. quinoa starch $(20 \%(\mathrm{w} / \mathrm{v}))$ in $\mathrm{pH} 5.0$ buffer solutions was cooked in boiling water and stirred vigorously for $30 \mathrm{~min}$. The cooked starch was adjusted to $58^{\circ} \mathrm{C}$. After an $8 \mathrm{~h}$ incubation period, the hydrolyses was centrifuged $(3000 \mathrm{~g}, 5 \mathrm{~min})$. The sediment was discarded and the supernatant was heated to $100^{\circ} \mathrm{C}$ for $10 \mathrm{~min}$, after which the supernatant was cooled to room temperature. The solution was stored at $4{ }^{\circ} \mathrm{C}$ for $8 \mathrm{~h}$ to self-assembly of the short-amylose. The suspensions were washed several times with distilled water until neutrality and then freeze dried to obtain Starch nanoparticles according to Suisui et al., ${ }^{10}$

Extraction of phenolic compounds from Luria Leaves and pomegranate peels: The air-dried ground $(80 \mathrm{mesh})$ plant material ( $20 \mathrm{~g}$ for each sample) was extracted with each of the solvents ethanol (ethanol: water, 80:20 v/v) and aqueous methanol (methanol: water, $80: 20 \mathrm{v} / \mathrm{v})(200 \mathrm{ml})$ for 6hours at room temperature in an orbital shaker in a water bath in separate experiments. The extracts were separated from the residues by filtering through Whatman No.1 filter paper. The residues were extracted twice with the same fresh solvent and extracts combined. The combined extracts were concentrated and freed of solvent under reduced pressure at $45^{\circ} \mathrm{C}$, using a rotary evaporator. The dried crude concentrated extracts were weighed to calculate the yield and stored in a refrigerator $\left(-4^{\circ} \mathrm{C}\right)$ according to Bushra et al., ${ }^{13}$ In this part of investigation, we used crude phenolic compounds extracts (as antioxidants)are prepared by adding ( 0.5 to $4.5 \%)$ acetic acidglacial adhesionthe described film formation solution mentioned above was modified. Acetic acid gives effect to total extracted as the highest antioxidant activity, which were acidified with $1-5 \%$ acetic acid. Maceration was conducted for $1 \mathrm{~h}$ at ambient temperature in a dark place according to Nyi Mekar Saptarini et al., ${ }^{22}$ Olafsson.,et al., ${ }^{23}$ and Nelson et al., ${ }^{6}$

\section{Preparation of produce edible films from quinoa protein and} starch nanoparticles

Preparation of quinoa protein films: A suspention was produced quinoa protein $(6.7 \mathrm{~g}$ protein $/ 100 \mathrm{~g}$ film-forming solution); cross linking agent $(0.8 \mathrm{~g}$ glutaraldehyde), and plasticizer $(5.2 \mathrm{~mL}$ of glycerol). Then the addition of 5\% previously prepared extracts from crude phenolic compounds extract (as antioxidants). The $\mathrm{pH}$ of the mixtures was adjusted to 10 and stirring was continued for $1 \mathrm{~h}$. The resulting blend was filtered under vacuum. The blend $(50 \mathrm{~mL})$ was cast on a horizontal surface in plate, measuring $(\sim 20 \times 20 \mathrm{~cm})$. The films were dried to constant weight at $50{ }^{\circ} \mathrm{C}$ the dried films were peeled carefully from the plate. ${ }^{24}$

Preparation of quinoa starch films nanoparticles: Quinoa starch powder $(4 \mathrm{~g} / 100 \mathrm{ml}$ total film solution) was dispersed in deionized water at room temperature and stirred for at least $1 \mathrm{~h}$ on a magnetic stirrer. The $\mathrm{pH}$ values (9.7-11.3) was then adjusted to using a $1 \mathrm{~N}$ $\mathrm{NaOH}$ solution, starch granule disruption during the gelatinization process. Then the addition of $5 \%$ previously prepared extracts from crude phenolic compounds extract (as antioxidants). After adjusting the $\mathrm{pH}$, magnetic stirring was continued for at least one more hour, and the dispersion then heated to $50^{\circ} \mathrm{C}$, and maintained at this temperature 
for a further $45 \mathrm{~min}$, with gentle magnetic stirring. The quinoa starch dispersion was gelatinized at $97^{\circ} \mathrm{C}$ for $30 \mathrm{~min}$ with constant stirring in a water bath. Then, glycerol was then added $6.3 \mathrm{~g}$ and stirring continued for another $15 \mathrm{~min}$ in order to completely homogenize the. The solution was then poured evenly onto plates $(\sim 20 \times 20 \mathrm{~cm})$. The films were dehydrated in an oven with air renewal and circulation and controlled temperature $50^{\circ} \mathrm{C}$. According to Patricia Araujo-Farro et al., ${ }^{20}$

The substances used in this experiment edible films were divided into six groups and for the modification of matrix composition of studied edible films

In this trial, the described film formation solution mentioned above was modified by adding and divided into six equal parts: One part (A) was film-forming based quinoa protein nano particles only glutaraldehyde and glycerol, second part (B) was film-forming quinoa protein nanoparticles with the incorporation of $(0.5 / 4.5 \%)$ crude phenolic compounds extracts (as antioxidants) luria leaves/ acetic acid glacial, third part (C) was film-forming quinoa protein nano particles with the incorporation of $(0.5 / 4.5 \%)$ crude phenolic compounds extracts (as antioxidants) pomegranate Peels/acetic acid glacial, four part (D) was film-forming basedquinoa starch nano particles only glycerol, five part (E) was film-forming quinoa starch nano particles with the incorporation of $(0.5 / 4.5 \%)$ crude phenolic compounds extracts (as antioxidants) luria leaves/acetic acid glacial and the six part $(\mathrm{F})$ was film-forming quinoa starch nano particles with the incorporation of $(0.5 / 4.5 \%)$ crude phenolic compounds extracts (as antioxidants) pomegranate Peels/acetic acid glacial.

Physical and mechanical and Rheological properties from quinoa protein and starch nano particles to produce edible films

i. Rheological measurements: Rheological parameters (shear rate and shear stress) of the selected edible natural filmswere measured using a Brookfield Engineering labs DV-III Rheometer at different temperature $\left(20,50\right.$ and $\left.80^{\circ} \mathrm{C}\right)$ of selected the most suitable solutions. The samples were placed in a small sample adapter and a constant temperature water bath was used to maintain the desired temperature. The viscometer was operated between 10 and 60rpm. The sc4-25 spindle was selected for the measurement.

ii. Zeta sizer nano Company name: Malvern, UK. Model:Zeta sizer nano series (Nano ZS).Size range (nm):0.6:6000nm Zeta potential range (mV): (-200:200mV) and XR- Diffraction. Model:XPERT-PRO-PA Nalytical-Netherland.

iii. Measurement of prepared edible films using scanning electron microscopy by: INSPECT S- SEM schematic overview-TM 1999-2007 Bwilddate, FEL company Euld number D 8571 Machine type inspect S. ${ }^{25}$

iv. Film thickness: The thickness of the prepared edible natural films from quinoa protein and starchnano particles(A,B,C,$\mathrm{D}$,E, and $\mathrm{F}$ )was measured using a digital micrometer (mitutoyo digimatic indicator corporation, model: pk-1012 E, Japan). Film strips were placed between the micrometer jaws and gap and was slowly reduced until the first contact was noted. ${ }^{26}$

v. Loss of film weight in water: The filmsnanoparticlesat different treatments (A,B,C,D,E, and F) specimens were first dried in a desicator containing dry calcium chlorides. Dry film sample of $500 \mathrm{mg}$ were immersed in beakers containing $50 \mathrm{ml}$ of distilled water at room temperature during $24 \mathrm{~h}$ with periodical gentle shaker incubator. Films were removed from the water and placed back in the desicator until constant weight. Loss weight in water was reported as a percentage of weight loss in water on dry film basis as follow: \% weight loss $=$ initial dry weight -final dry weight $\times 100$ / initial dry weight according to Munoz et al., ${ }^{27}$

vi. Mechanical properties of edible film from quinoa protein and starch nano particles: Measurement of treated (A,B,C,$\mathrm{D}$, E, and F) nanoparticles films, the tensile properties (Tensile strength, elongation) were measured by a texture analyzer CT3. The films nanoparticles at different treatments (A,B,C,$\mathrm{D}$,E, and F)were cut into strips $3 \times 5 \mathrm{~cm}$. These were gripped at each end by a jaw and then the jaws were moved a part at the controlled speed until and young's modulus was automatically recorded according Hernandez et al., ${ }^{28}$

vii. Measurements of Water vapor permeability (WVP):The water vapor transmission rate $\left[\mathrm{g} /\left(\mathrm{s} . \mathrm{m}^{2}\right)\right]$ and water vapor permeability through films was determined gravimetrically using the ASTM Method E96-95. A circular test cup was used to determine the WVP of the films nanoparticles at different treatments (A,B,C,D,E, and F). The film was first cut into circular shape that was larger than the inner diameter of the cup, the cup was filled with 50\% distilled water and the film was sealed at the top using Paraffin oil, then the cups were placed in a desiccator containing calcium chloride. The weights of the cups were recorded every hour during 10 hours and specimens of each film were tested. Linear regression was used to estimate the slope of this line in $\mathrm{g} / \mathrm{h}$. The water vapor transmission rate (WVTR) and water vapor permeability was determined using the following: WVPR $=\Delta m$ $\mathrm{WVP}=$ WVTR. $\mathrm{L} / \Delta R H$

Where, $\Delta m / \Delta t$ is the moisture gain weight per time $(\mathrm{g} / \mathrm{s})$, A is the surface area of the film $\mathrm{m} 2, \mathrm{~L}$ is the film thickness (mm) and $\triangle R H$ is the difference in relative humidity.(ASTM E96-95).

viii. Measurement of gas Permeability

Gas (O2 and $\mathrm{CO} 2)$ permeability at $30^{\circ} \mathrm{C}$ was measured in a designed stainless cell using a gas testing instrument, model Witt Oxybaby headspace gas analyser $\left(\mathrm{O}^{2} / \mathrm{CO}^{2}\right)$ following the method described by García et al. ${ }^{29}$ The gas permeability $(\mathrm{P})$ was calculated according to the following equation:

$$
P=Q . X / A . t . \Delta \mathrm{p}
$$

Where, $\mathrm{P}$ is the permeability of gas, $\left(\mathrm{m}^{3} / \mathrm{m}\right.$. day. $\left.\mathrm{mmHg}\right), \mathrm{Q}$ is the quantity of gas diffused $\mathrm{m}^{3}, \mathrm{X}$ is the thickness of film, A area of the film, $\mathrm{m}^{2}, \mathrm{t}$ is the time, day and $\Delta \mathrm{p}$ is the pressure difference across the films nanoparticles at different treatments (A,B,C,D,E, and F).

\section{Results and discussion}

\section{Rheological properties of edible film from quinoa protein and starch nano particles}

Rheological properties (viscosity, shear stress) of samples treatments (A,B,C,D,E and F) were measured at different temperatures $\left(20,50\right.$ and $\left.80^{\circ} \mathrm{C}\right)$ and different shear rates $(9.30,18.60,27.90,37.20$, $46.50,55.80,65.10,74.40,83.70,931 / \mathrm{s})$. Figure 1 Shows as to choose the best most suitable solutions prepared edible natural films from quinoa protein and starch nanoparticles were shown in Table 1 and Figures 1-6. The results show that the forming solution exhibits trend of non-Newtonian pseudoplastic behavior at different treatment (A,B,$\mathrm{C}, \mathrm{D}, \mathrm{E}$ and $\mathrm{F}$ ) and fits the power low equation $\tau=\mathrm{k} \gamma^{\mathrm{n}} \rightarrow(1)$ Where: $\tau$ : shear stress, Pa $\gamma$ : shear rate $1 / \mathrm{sec}, \mathrm{k}$ : consistency index, n: flow behavior index. The results observed that apparent viscosity decrea- 
sed as shear rates increased at different temperatures $\left(20,50\right.$ and $\left.80^{\circ} \mathrm{C}\right)$ and Figures (1a , 2b , 3c , 4d,5e \& 6f ), the results observed that sample A exhibited non-Newtonian pseudoplastic behavior as previously discussed by Suisui et al., ${ }^{10}$ who found that the apparent viscosity increased with increasing concentrations of starch nano particles. The dispersibility of the nano-scale starch particles in aqueous solution is reflected by the rheological properties, which are important for their application both when they are used alone and when they are part of a mixture. The viscosity values of starch nanoparticles suspensions containing different concentrations the aqueous suspensions of starch nano particles exhibited shear-thinning behavior, indicating that they were non-Newtonian fluids. All samples B,C,D,E and Fexhibited the same trend as sample A, $a$ s previously discussed by Wittmar et al., ${ }^{30}$ who stated that nanoparticales was strongly affected by ionic liguid.

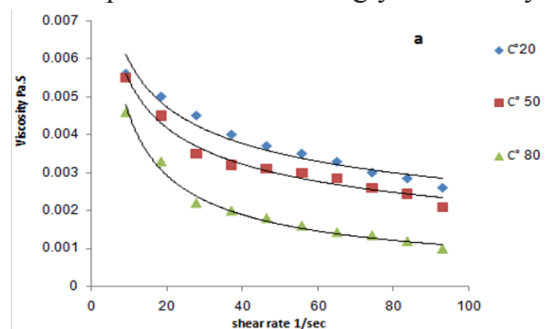

Figure Ia Effect of shear rate on apparent viscosity of treatment (a) at different temperatures.

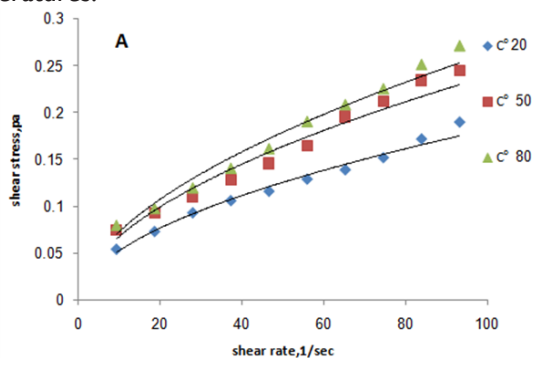

Figure IA Effect of shear rate-shear stress of treatment (A) at different temperatures.

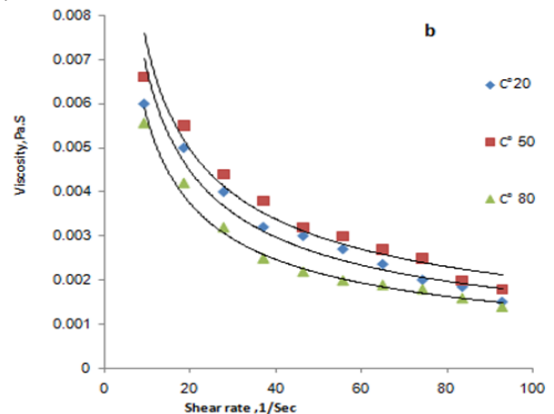

Figure $\mathbf{2 b}$ Effect of shear rate on apparent viscosity of treatment (b) at different temperatures.

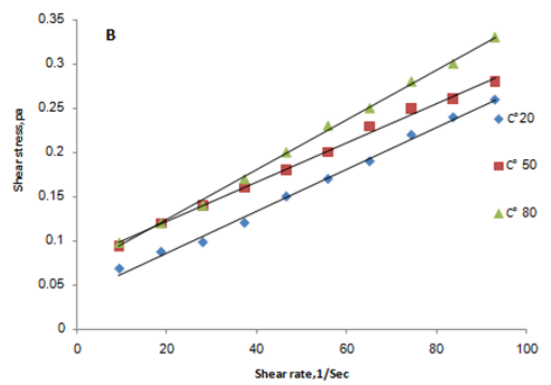

Figure 2B Effect of shear rate - shear stress of treatment (b) at different temperatures.

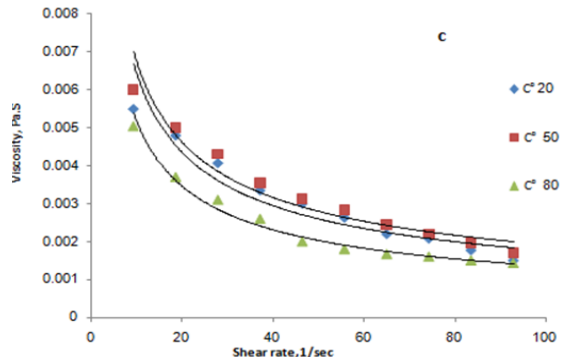

Figure 3c Effect of shear rate on apparent viscosity of treatment (c) at different temperatures.

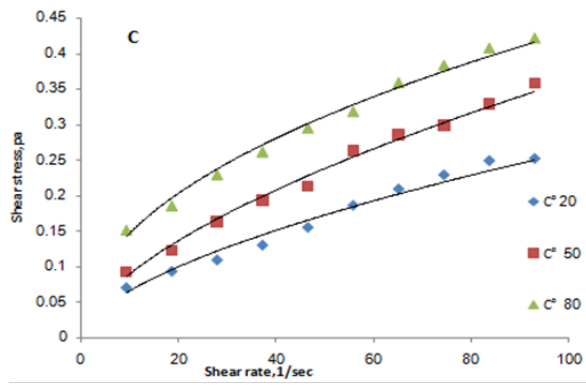

Figure 3C Effect of shear rate - shear stress of treatment (c) at different temperatures.

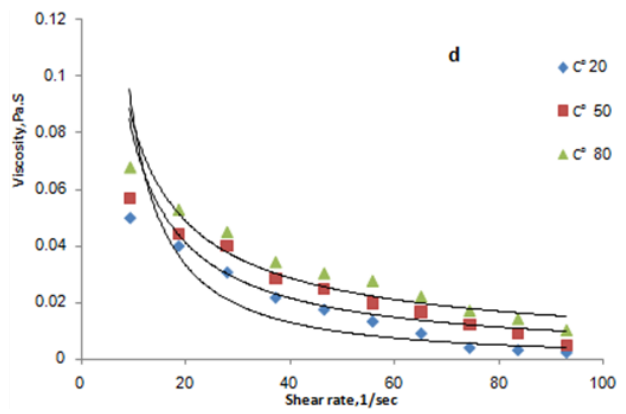

Figure 4d Effect of shear rate on apparent viscosity of treatment (d) at different temperatures.

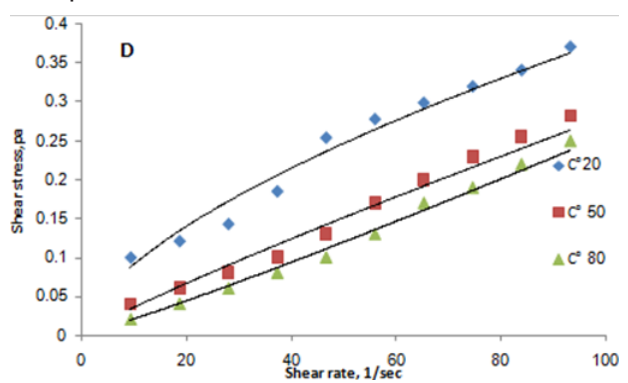

Figure 4D Effect of shear rate - shear stress of treatment (d) at different temperatures

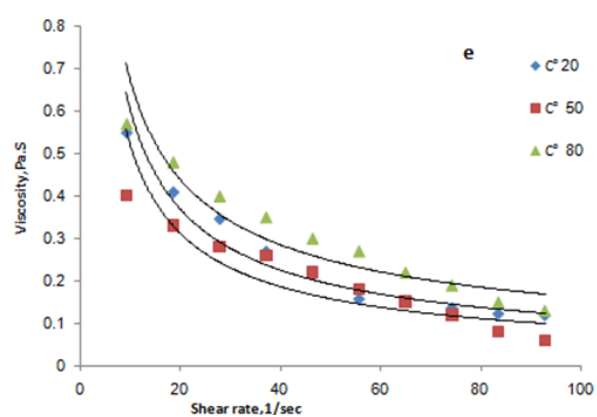

Figure 5e Effect of shear rate on apparent viscosity of treatment at different temperatures. 


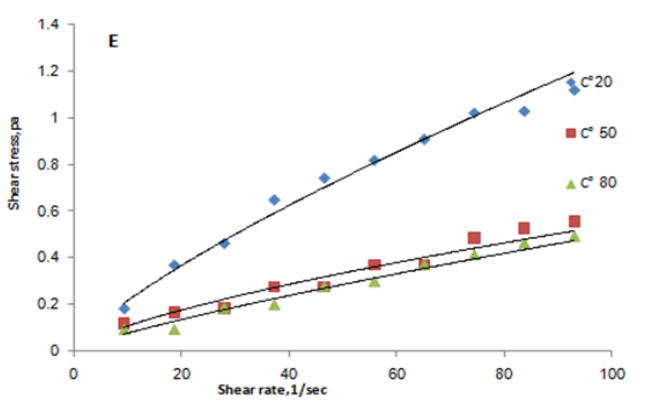

Figure 5E Effect of shear rate - shear stress of treatment (e) at different temperatures.

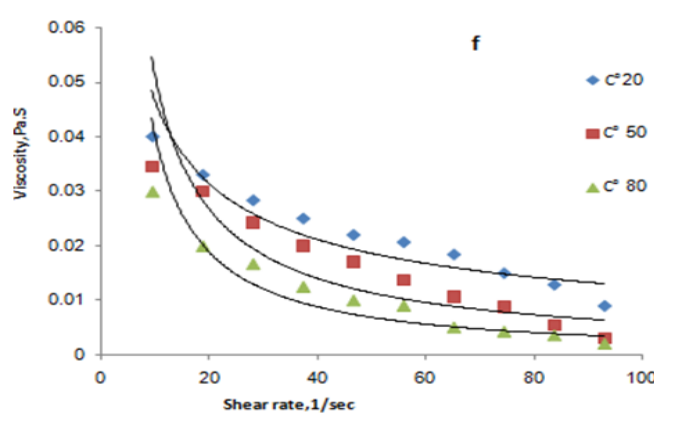

Figure 6F Effect of shear rate - shear stress of treatment (f) at different temperatures.

The viscosity of the starch dispersion increased at around $80^{\circ} \mathrm{C}$. The influence of hydrocolloids (media, distilled water) on the viscosity of starch dispersions during heating, a mixture starch of various ingredients or elements varied depending on the particular hydrocolloid added. In Table 1 shows the power low para meters $k$, $n$ the results observed that consistency index $k$ for sample A and $\mathrm{C}, \mathrm{E}$ and $\mathrm{D}$ increase with increasing temperature while samples F,B didn't give a good trend with increasing temperature. Flow behavior index $n$ increased with increasing temperature for sample A and D,

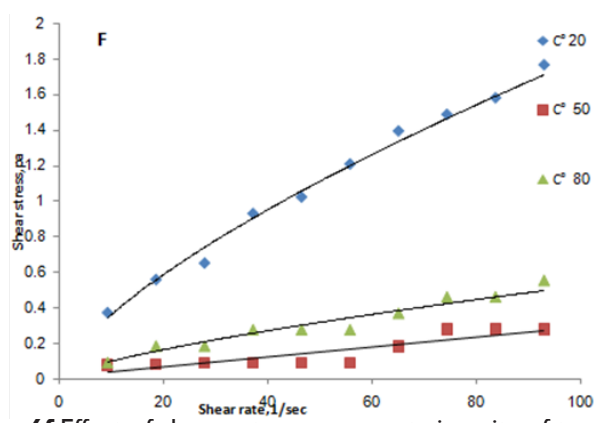

Figure $6 f$ Effect of shear rate on apparent viscosity of treatment (f) at different temperatures.

where as decreased for sample B and give no trend for samples C,E and F. When shear force, associated with temperature, was applied, the particles would undergo rearrangement among themselves in a direction parallel to the shear force. The particleparticle interaction is disrupted as particles tend to undergo vibration at higher temperature. Also, at higher temperature, many big particles would break into smaller particles Keshani et al. ${ }^{31}$ When an aqueous starch dispersion is heated to its gelatinization temperature, the starch granule swells irreversibly according to Hua et al. ${ }^{32}$ While, shows a representative flow curve shear stress increased with increasing shear rate at different temperatures 25 and $70^{\circ} \mathrm{C}$, and the extend of downwared bending curvature decreased as the concentration of blend suspentions was decreased. Apparent viscosity decreased with increase of $k$ at each level of concentration, ${ }^{33,34}$ The results indicated that the behavior of the liquid solution and the type and size of particles, as well as the presence of ionized substances and electrolytes. The decrease in viscosity can be attributed to the increase in intermolecular distances, because of the thermal expansion caused by the increase in temperature .The viscosity decreased with an increase in temperature up to $50^{\circ} \mathrm{C}$; however, at $60^{\circ} \mathrm{C}$, an increase tendency in viscosity was found. This increase tendency is due to a possible starch gelatinization in the whole araca pulp. ${ }^{35}$

Table I Relation between consistency index $(k)$ and flow behavior index $(n)$ at different temperature $\left(20,50\right.$ and $\left.80^{\circ} \mathrm{C}\right)$ properties from quinoa protein and starch nano particles to produce edible natural films

\begin{tabular}{|c|c|c|c|c|c|c|c|c|c|}
\hline \multirow{2}{*}{ Treatments } & \multicolumn{3}{|l|}{$20^{\circ} \mathrm{C}$} & \multicolumn{3}{|l|}{$50^{\circ} \mathrm{C}$} & \multicolumn{3}{|l|}{$80^{\circ} \mathrm{C}$} \\
\hline & k & $n$ & $\mathbf{R 2}$ & k & $\mathbf{n}$ & $\mathbf{R 2}$ & $k$ & $\mathbf{N}$ & $\mathbf{R 2}$ \\
\hline A & 0.0159 & 0.5293 & $0.988 I$ & 0.0197 & 0.5417 & 0.9629 & 0.0205 & 0.5538 & 0.9718 \\
\hline B & 0.0022 & 0.077 & 0.9962 & 0.0028 & 0.0679 & 0.998 & 0.0024 & 0.039 & 0.9948 \\
\hline C & 0.0165 & 0.5995 & 0.9744 & 0.0225 & 0.6025 & 0.9893 & 0.05 & 0.4673 & 0.988 \\
\hline D & 0.0217 & 0.6211 & 0.9575 & 0.0046 & 0.8915 & $0.977 \mid$ & 0.0016 & I. 1074 & 0.9946 \\
\hline$E$ & 0.0368 & 0.7679 & 0.9877 & 0.0226 & 0.691 & 0.9565 & 0.0119 & 0.8152 & 0.9439 \\
\hline$F$ & 0.0742 & 0.6924 & 0.9884 & 0.0028 & 0.01111 & 0.7876 & 0.0192 & 0.7183 & 0.9523 \\
\hline
\end{tabular}

A= Film-forming based quinoa protein, glutaraldehyde, glycerol. B= Film-forming quinoa protein nanoparticles with addition of (0.5/4.5\%) crude phenolic compounds extracts luria leaves/acetic acid glacial. $\mathrm{C}=$ Film-forming quinoa protein nanoparticles with addition of $(0.5 / 4.5 \%)$ crude phenolic compounds extracts pomegranate Peels/ acetic acid glacial $\mathrm{D}=$ Film-forming based quinoa starch, glycerol. $\mathrm{E}=$ Film-forming quinoa starch nanoparticles with addition of $(0.5 / 4.5 \%)$ crude phenolic compounds extracts luria leaves/acetic acid glacial. F= Film-forming quinoa starch nanoparticles with addition of $(0.5 / 4.5 \%)$ crude phenolic compounds extracts pomegranate Peels/ acetic acid glacial. 
Determination of partical size distribution and Zeta potentioal produced films and $\mathrm{X}$-R diffraction (XRD) films of quinoa protein and starch nano particles on based film and solution formed from it:

\section{partical size distribution:}

The results obtained are present in table 2 and Figure 7 shows the quinoa protein and starch nano particles on the properties of the dispersion of film and solution evaluated based on the change in size (z-average) and the z-potential of the nanoparticles relative to the fil$\mathrm{ms}$ of protein and starch nano particles on based film and solution formed sample, poly dispersity index (PdI) in the peak was 0.397 , $0.649,0.549,0.789,0.578$ and 0.527 for $\mathrm{A}, \mathrm{B}, \mathrm{C}, \mathrm{D}, \mathrm{E}$ and $\mathrm{F}$ respectively as well as hydrodynamic diameter of partical size in the peak was 280.9, 55.61, 84.13, 156.8, 68.66 and 73.51 for A, B, C, D, E and $\mathrm{F}$ respectively. Starch was dissolved in an aqueous solution with the size of about $90-300 \mathrm{~nm}$, depending on the concentration, temperature and $\mathrm{pH}$ of aqueous solution. ${ }^{36}$ Jong and Seung. Which similar to the findings of Jie Xiao et al., ${ }^{37}$ who found that nano materials with, chitosan, polysaccharides (maize starch) and proteins were 240, 360 and 90-340nm respectively. These results are in agreement with. Nelson et al., ${ }^{6}$ found that the suspentions containing starch nanocrystals range from 310,384 and $417 \mathrm{~nm}$. The starch nanoparticles were observed to be spherical in shape, with particle sizes primarily within the range of 200-300nm. The difference in shape can be attributed to the fact that the formation of the starch nanocrystals was different from that of the starch nanoparticles. The starch nanocrystals were prepared by sulfuric acid hydrolysis of the more amorphous phase of the native. ${ }^{10}$
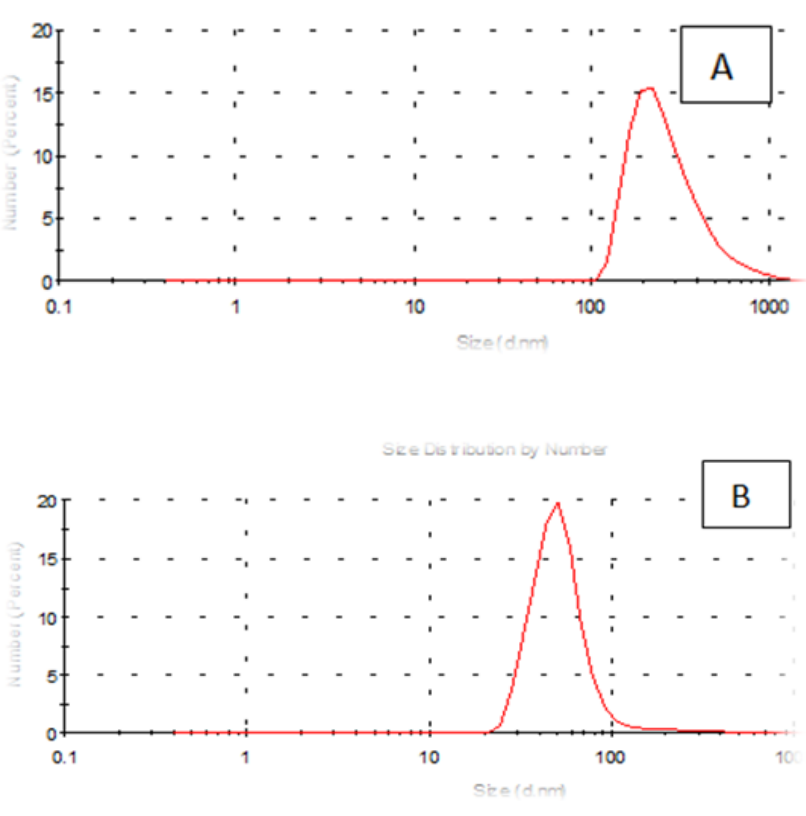
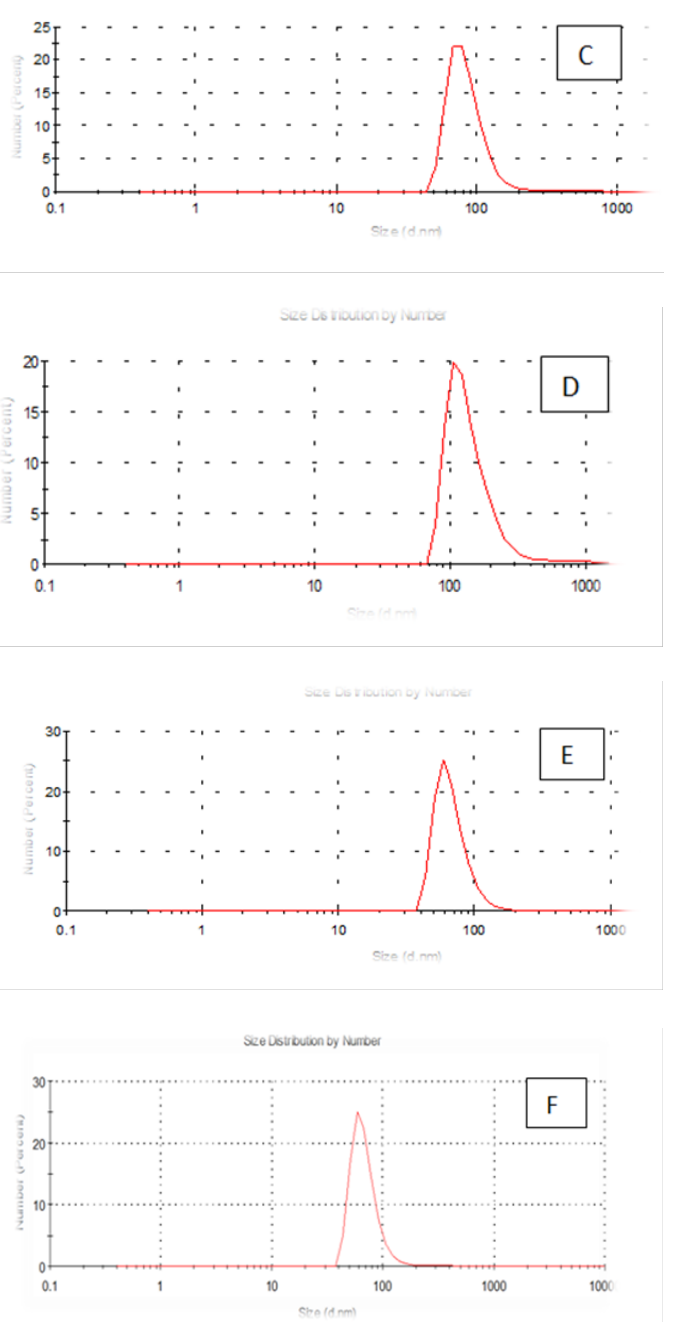

Figure 7 (A-F) Partical size of produced films

A= Film-forming based quinoa protein,glutaraldehyde,glycerol. B= Filmforming quinoa protein nanoparticles withaddition of $(0.5 / 4.5 \%)$ crude phenolic compounds extracts luria leaves/acetic acid glacial. $C=$ Film-forming quinoa protein nanoparticles withaddition of $(0.5 / 4.5 \%)$ crude phenolic compounds extracts pomegranate Peels $/$ acetic acid glacial. $D=$ Film-forming based quinoa starch, glycerol. E= Film-forming quinoa starch nanoparticles with addition of $(0.5 / 4.5 \%)$ crude phenolic compounds extracts luria leaves/ acetic acid glacial. F= Film-forming quinoa starch nanoparticles with addition of $(0.5 / 4.5 \%)$ crude phenolic compounds extracts pomegranate Peels/acetic acid glacial.

\section{Zeta potential}

From the Table 2 \& Figure 8, the results showed that Zeta potentioal distribution and Zeta Deviation was measured to determine the stablity of nano partical, it depends on the nano partical sizeof protein and starch, solution, $\mathrm{pH}$ and electrical properties. The results observed that samples A Zeta potential distribution $(\mathrm{mV})$ : 25.3 and Zeta Deviation $(\mathrm{mV}): 7.55$, As found in the chracterization of the two peak of zeta potential in the first peak $27.0(\mathrm{mV})$, the area below the curve was $89.8 \%$ and the second peak $7.96(\mathrm{mV})$, the area below the curve was $10.2 \%$. However, found that the chracterization of the one peak of zeta potential distribution and Zeta Deviation the area below the curve was $100 \%$ found that the contentes of Zeta potentioal in the peak different tretments B, C, D, E and F had zeta potentioal 16.3, 12.2, 
$14.9,4.82$ and $15.0(\mathrm{mV})$ respectively, as well as the contentes of zeta deviation in the peak different treatments B, C, D, E and F had zeta deviation $2.80,5.85,4.29,14.4$ and 18.7 respectively. ${ }^{6}$ Zeta potential gauges the electric charge at the boundary of a colloidal particle, and it is an important index for its surface charge. Zeta potential determines the electrostatic repulsion among them and is accountable for their stability against precipitation, and it is usually obtained by measuring and converting from the electrophoretic mobility of the particles. As recommended by Zi Teng et al. ${ }^{15}$ and American Society for Testing $\&$ Materials ${ }^{38}$ zeta potentials with an absolute value of higher than $30 \mathrm{mV}$ are indicative for "moderate to good" stability of colloidal systems(ASTM). The higher the zeta potential, the better the stability of a dispersion. A desirable zeta potential could be obtained by Teng et al., ${ }^{15}$ choosing highly charged polymers (e.g., protein or chitosan) as an encapsulant. On the other hand, when poorly charged materials (e.g., zein) are employed for encapsulation, a second layer of highly charged polymers may be introduced to improve the dispersion stability. ${ }^{15}$

\section{Structural characterization of producin films measured by X-R diffraction(XRD).}

From the results in Table $2 \&$ Figure 9 Showed that the data were in the peak different treatments X-R diffraction(XRD) Position [ ${ }^{2}$ Theta] [\%]pattern of samples A, B, C, D, E and F, the (XRD) below the typical Pattern -type peek at ${ }^{\circ} 2$ Theta $=23.55,59.93,6.75,39.66$, 46.19 and 12.81 respectively while, the (XRD) above the peak at ${ }^{\circ} 2$ Theta $=5.76,21.61,31.79,20.22,21.06$ and 42.63 respectively.
Some of the detected peaks, such as the treatments A, D the diffractogram exhibits four distinct diffraction of samples A the peak at ${ }^{\circ} 2$ Theta $=23.55,18.0,11.06$ and 5.76 they matches of samples D, 39.66, $9.53,6.48$ and 20.22 of samples B exhibits five distinct diffraction the peak at ${ }^{\circ} 2$ Theta $=59.93,32.16,30.91,27.72$ and 21.61 they matches the diffraction of samples $\mathrm{C}$ the peak at ${ }^{\circ} 2$ Theta $=6.75,9.39,13.70$, 20.0823 .28 and 31.79 and the samples E, F exhibits seven and six distinct diffraction the peak at ${ }^{\circ} 2$ Theta $=\mathrm{E}, 46.19,41.19,32.30,28.28$ $, 26.19,22.44$ and 21.06 they matches distinct diffraction of samples the peak at ${ }^{\circ} 2$ Theta $=F, 12.81,21.17,23.23,26.32,31.17$ and 42.63 . The chitosan/quinoa proteins film exhibited sharp, well-defined peaks at ${ }^{\circ}$ Theta (20.0 and 29.4) that are more intense than those observed in the chitosan film. The chitosan/quinoa proteins film also exhibited diffraction peaks at ${ }^{\circ} 2$ Theta $(35.9,39.4,43.2$ and 47.5) suggesting intermolecular interactions between the quinoa proteins and chitosan Valenzuela et al., ${ }^{39} \mathrm{X}$-ray diffraction patterns of the complex particles are presented the particles yielded a type XRD pattern with two broad reflections at d-spacings 0.657 and $0.446 \mathrm{~nm}$ (13.08 and 19.78 $\left.{ }^{\circ} 2\right)$. However, the XRD diagram revealed that the crystallinity was only partial with an overlapping amorphous background. The starch nano-particles isolated by hydrolysis also exhibited a type XRD pattern with four sharp reflections atd-spacings $1.187,0.685,0.448$ and $0.394 \mathrm{~nm}\left(7.44,12.91,19.79\right.$ and $\left.22.54^{\circ} 2\right)$. The XRD revealed that the a-amylolysis occurred mainly in the amorphous region of the complex, leaving the crystalline nanoparticles. ${ }^{36}$ Similar results were found by Jie Xiao et al., ${ }^{37}$ Suisui et al., ${ }^{10}$ These different peaks are associated with surface deposits in both types nano materials films. ${ }^{11}$
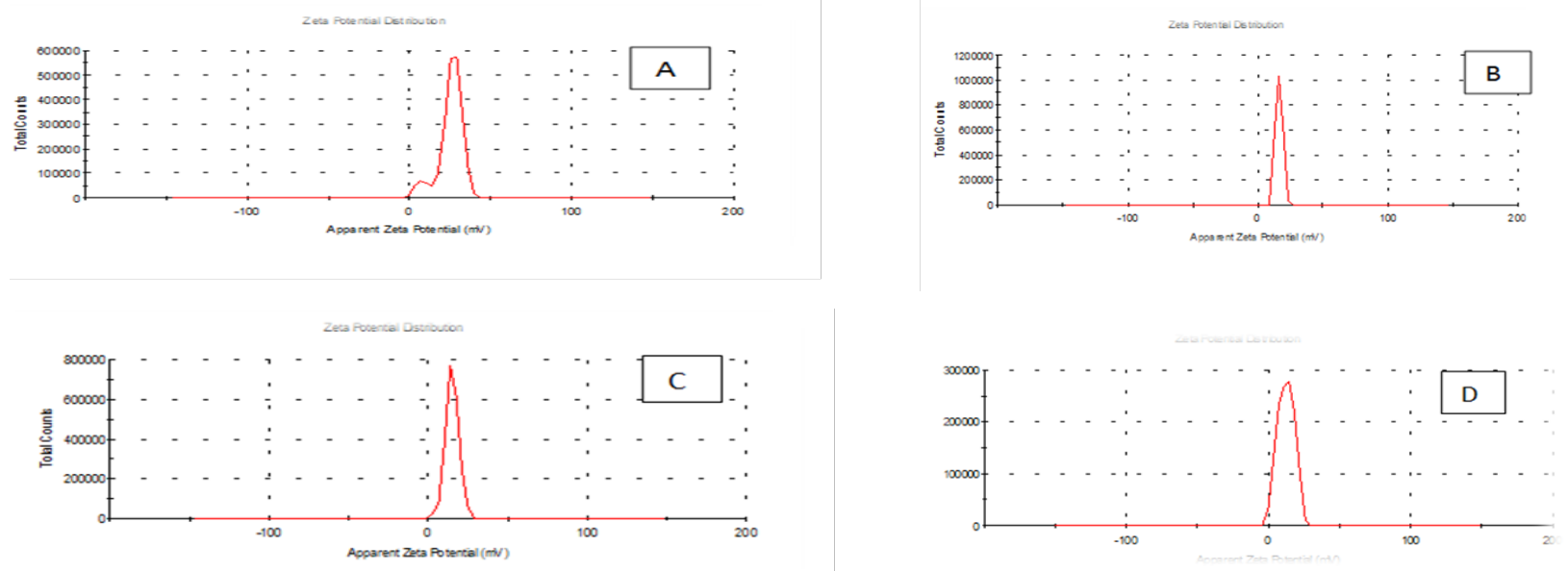

Zeta Potential Dstrbution
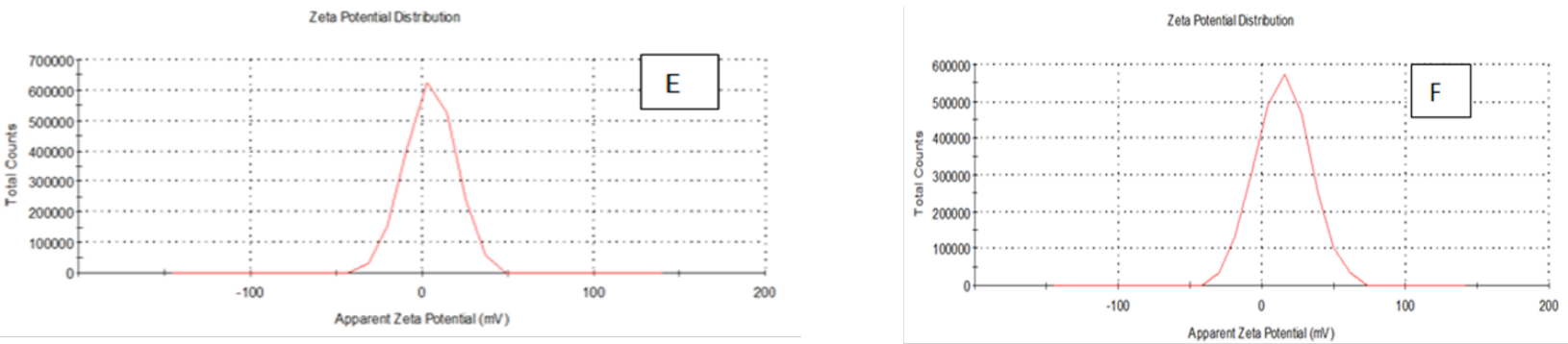

Figure 8 A,B,C,D,E \& F zeta potential of produced films

A= Film-forming based quinoa protein, glutaraldehyde, glycerol. B= Film-forming quinoa protein nanoparticles with addition of (0.5 / $4.5 \%)$ crude phenolic compounds extracts luria leaves/acetic acid glacial C= Film-forming quinoa protein nanoparticles with addition of (0.5/4.5\%) crude phenolic compounds extracts pomegranate Peels / acetic acid glacial $D=$ Film-forming based quinoa starch, glycerol.E= Film-forming quinoa starch nanoparticles with addition of $\mathbf{( 0 . 5 / 4 . 5 \% )}$ crude phenolic compounds extracts luria leaves / acetic acid glacial F= Film-forming quinoa starch nanoparticles withaddition of (0.5/4.5\%) crude phenolic compounds extracts pomegranate Peels/acetic acid glacial. 

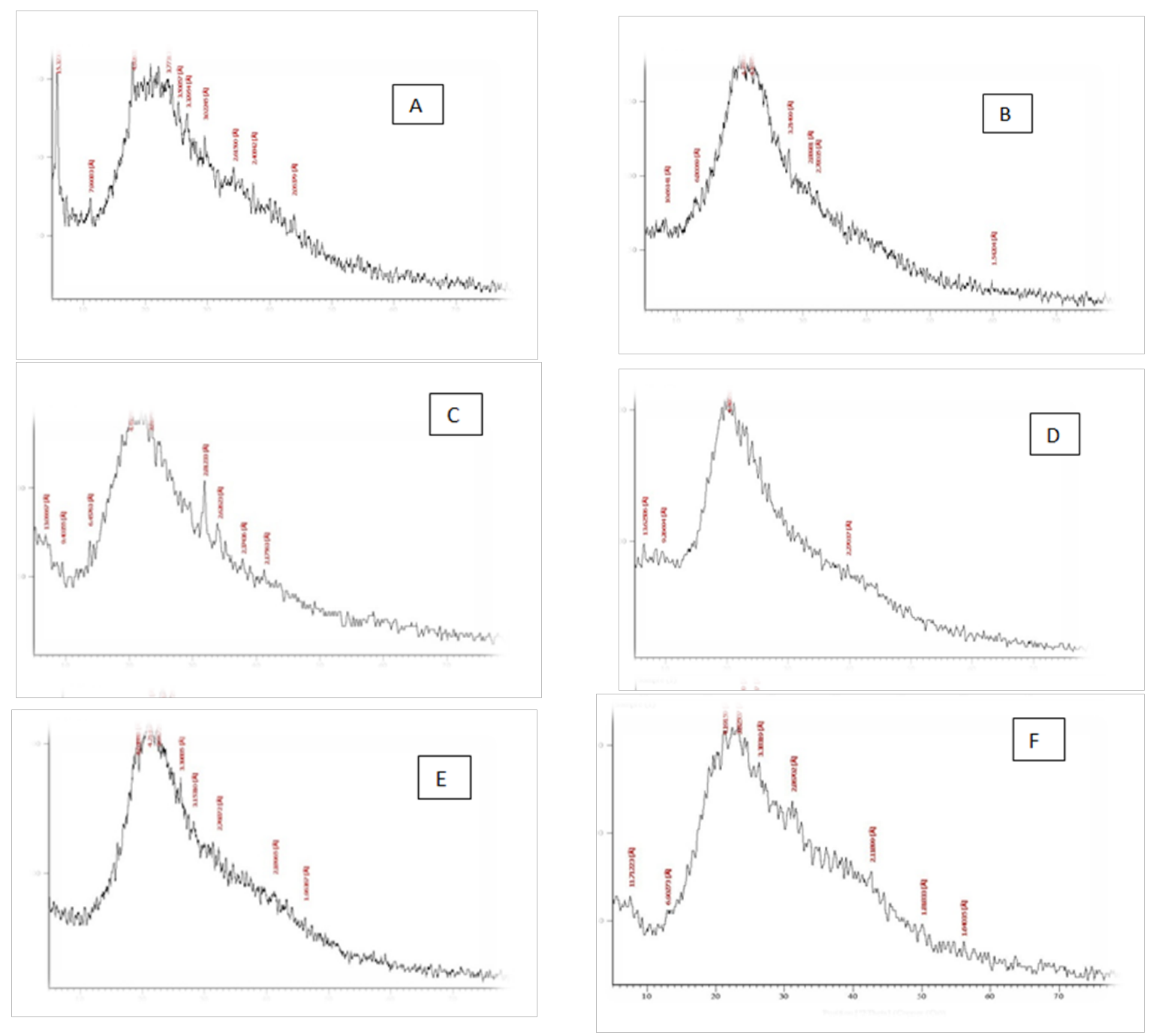

Figure 9 A,B,C,D,E \& F X-R diffraction of produced films

A= Film-forming based quinoa protein, glutaraldehyde, glycerol. B= Film-forming quinoa protein nanoparticles withaddition of $(0.5 / 4.5 \%)$ crude phenolic compounds extracts luria leaves/acetic acid glacial C= Film-forming quinoa protein nanoparticles with addition of $(0.5 / 4.5 \%)$ crude phenolic compounds extracts pomegranate Peels/acetic acid glacial $D=$ Film-forming based quinoa starch, glycerol.E= Film-forming quinoa starch nanoparticles withaddition of $(0.5$ / 4.5\%) crude phenolic compounds extracts luria leaves/acetic acid glacial F= Film-forming quinoa starch nanoparticles withaddition of ( 0.5 / $4.5 \%)$ crude phenolic compounds extracts pomegranate Peels/acetic acid glacial.

Table 2 Measured particles size, zeta potential and X-R diffraction of quinoa protein and starch suspensions as affected by temperature and added antioxidants produced films based formed from it

\begin{tabular}{|c|c|c|c|c|c|c|}
\hline \multirow{2}{*}{ Treatments } & \multicolumn{2}{|c|}{ Particle size distribution(nm) } & \multicolumn{2}{|c|}{ Zeta potential(mv) } & \multicolumn{2}{|c|}{$\begin{array}{l}\text { X-R diffraction(XRD) } \\
\text { ['2Theta] [\%] }\end{array}$} \\
\hline & $\begin{array}{l}\text { Poly dispersity } \\
\text { index (PdI) }\end{array}$ & $\begin{array}{l}\text { Hydrodynamic } \\
\text { diameter }(\mathrm{nm})\end{array}$ & $\begin{array}{l}\text { z- } \\
\text { potential }\end{array}$ & $\begin{array}{l}\text { z- } \\
\text { deviation }\end{array}$ & Above & Below \\
\hline A & 0.397 & 280.9 & 25.3 & 7.55 & 5.76 & 23.55 \\
\hline B & 0.649 & 55.61 & 16.3 & 2.8 & 21.61 & 59.93 \\
\hline C & 0.549 & 84.13 & 12.2 & 5.85 & 31.79 & 6.75 \\
\hline D & 0.789 & 156.8 & 14.9 & 4.29 & 20.22 & 39.66 \\
\hline$E$ & 0.578 & 68.66 & 4.82 & 14.4 & 21.06 & 46.19 \\
\hline $\mathrm{F}$ & 0.527 & 73.51 & 15 & 18.7 & 42.63 & $|2.8|$ \\
\hline
\end{tabular}

A= Film-forming based quinoa protein, glutaraldehyde, glycerol. B= Film-forming quinoa protein nanoparticles withaddition of (0.5/4.5\%) crude phenolic compounds extracts luria leaves/acetic acid glacial. C= Film-forming quinoa protein nanoparticles withaddition of (0.5/4.5\%) crude phenolic compounds extracts pomegranate Peels/acetic acid glacial $D=$ Film-forming based quinoa starch, glycerol. E= Film-forming quinoa starch nanoparticles with addition of $(0.5 / 4.5 \%)$ crude phenolic compounds extracts luria leaves/acetic acid glacial F= Film-forming quinoa starch nanoparticles with addition of (0.5/4.5\%) crude phenolic compounds extracts pomegranate Peels/acetic acid glacial. 


\section{Microstructure of the produced edible films using scanning electron microscopy (SEM)technique}

The microscopic images of six edible natural films from quinoa protein and starch nano particles are presented in figure (A,B,C,D,E, and F).The edible natural films give films characterised with smooth surface and rought bottom averge size from 40 to 50 um polygonal crystals spherical morphology. Also contains films has homogeneous structure with some micro granules embedded in a continuous matrix. However, the addition of protein and starch nano particles produced films the characterised with smooth surface Figure 10. Also, addition of antioxidant gave the thickness of produced films increase the degree of creamy color.The best nano edible natural films treatment image characterization was B average droplet size range (40um) polygonal crystals morphology followed by $\mathrm{E}$ average droplet size range (40um) spherical followed by $\mathrm{F}$ average droplet size range (50um) polygonal and ellipsoidal, $\mathrm{C}$ average droplet size range (50um) spherical, D average droplet size range (50 um) ellipsoidal and polygonal and A image characterization average droplet size range (40um) polygonal and spherical morphology. When a section was taken to characterize the nanosphere the image was $(\mathrm{B} 200 \mathrm{~nm})$ followed by $(\mathrm{E} 250 \mathrm{~nm})$ followed by (F285nm), (C290nm), (D 310nm) and (A was 345nm). ${ }^{40}$ The preparation of spherical particles of uniform size $(\sim 200 \mathrm{~nm})$ has been found to be rather narrow, with several other kinds of polydisperse aggregates and anisotropic structures being formed above or below the optimum $\mathrm{pH}(\sim 6)$ The partical size have a wide range of shapes and size according to Patricia et al. ${ }^{20}$ Franciele et al. ${ }^{14}$ As examined starch structure under scanning electron microscopy images depicted particles with diameter of $25-65 \mathrm{~nm}$ as noted that starch structure is composed of larger blocklets with size of $100-200 \mathrm{~nm}$ separated by gaps according to Mehdi et al. ${ }^{11}$
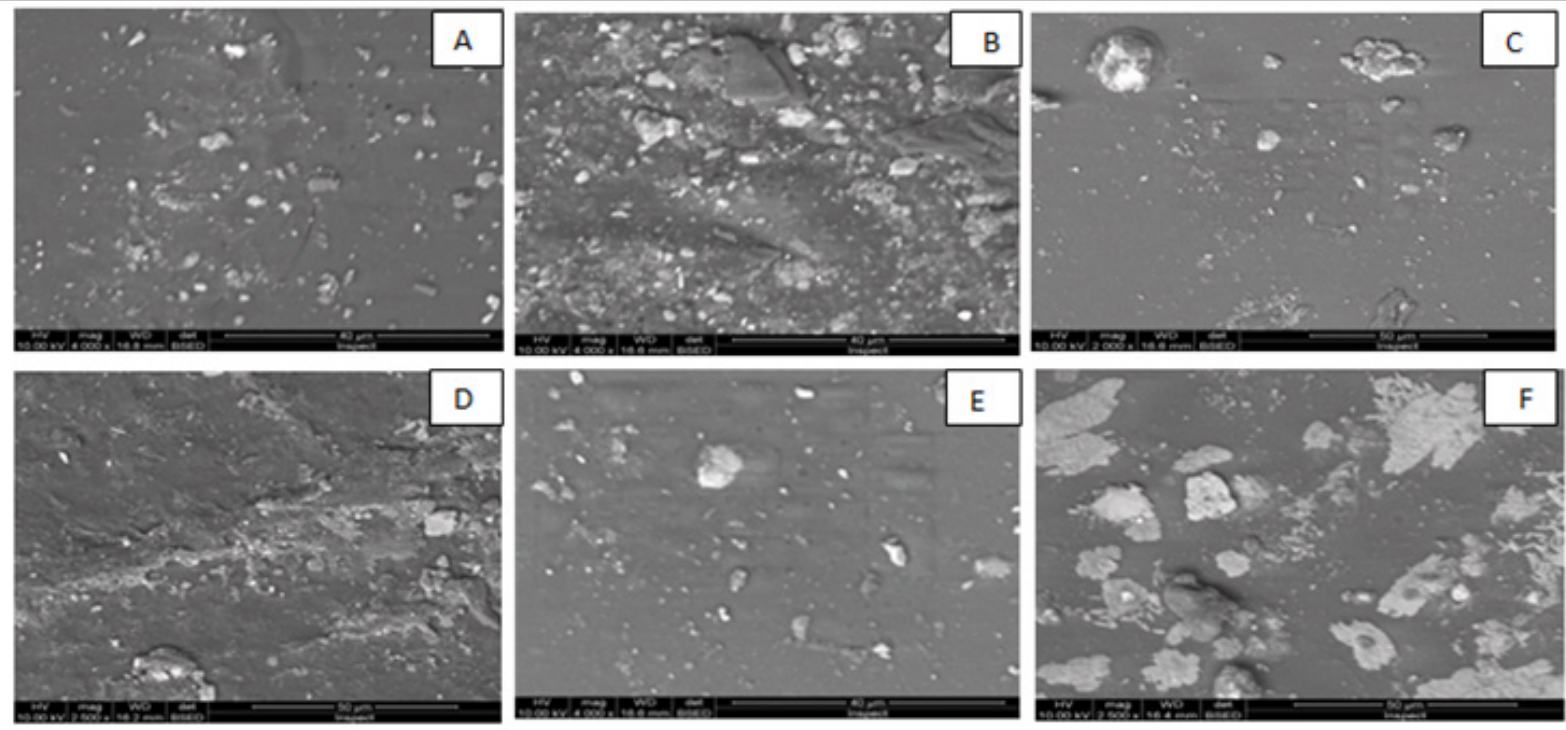

Figure IO A,B,C,D,E \& F SEM micrograph of produced Films

A= Film-forming based quinoa protein, glutaraldehyde, glycerol. B= Film-forming quinoa protein nanoparticles withaddition of (0.5/4.5\%) crude phenolic compounds extracts luria leaves/acetic acid glacial C= Film-forming quinoa protein nanoparticles with addition of (0.5/4.5\%) crude phenolic compounds extracts pomegranate Peels/acetic acid glacial $\mathrm{D}=$ Film-forming based quinoa starch, glycerol. E= Film-forming quinoa starch nanoparticles with addition of (0.5/4.5\%) crude phenolic compounds extracts luria leaves/acetic acid glacial F= Film-forming quinoa starch nanoparticles with addition of (0.5/4.5\%) crude phenolic compounds extracts pomegranate Peels/acetic acid glacial.

\section{Physical and mechanical properties of prepared quinoa protein and starch nano particles to produce edible films}

The obtained results are recorded in Table 3. It can be noticed that the $\mathrm{A}$ and $\mathrm{D}$ treatment, had the highest thickness value, 120 and110umin films prepared to produce edible natural films. The thickness of edible natural film B and E treatment was lower than C and F. From the results; it can be observed that the lowest value of tensile strength (95.23 and 80.34N.M.M ${ }^{2}$ ), elongation (40.10 and 38.75\%), (Oxygen 5.54 and $\left.7.15 \mathrm{M}^{3} \cdot \mathrm{M} / \mathrm{M}^{2} \mathrm{X}^{10-7}\right)$, (CO2 11.32 and $12.34 \mathrm{M}^{3} \cdot \mathrm{M} / \mathrm{M}^{2} \mathrm{X}^{10-}$ $\left.{ }^{8}\right)$, water vapors permeability 3.67 and $2.86\left[\mathrm{~g} / \mathrm{m}^{2} .24 \mathrm{hr}\right]$ and solubility (9.16 and $14.22 \%)$ was recorded for the treatment B and E. Also, A and D treatment showed higher tensile strength (24.26 and 50.00 N.M.M ${ }^{2}$ ), elongation (12.11 and 16.78\%), (Oxygen 25.32 and 19.87
$\left.\mathrm{M}^{3} \cdot \mathrm{M} / \mathrm{M}^{2} \mathrm{X}^{10-7}\right),\left(\mathrm{CO} 226.89\right.$ and $\left.24.56 \mathrm{M}^{3} \cdot \mathrm{M} / \mathrm{M}^{2} \mathrm{X}^{10-8}\right)$, Water vapors permeability $\left[0.79\right.$ and $1.22\left[\mathrm{~g} / \mathrm{m}^{2} .24 \mathrm{hr}\right]$ and solubility $(25.00$ and $22.32 \%$ ). While the treatment $\mathrm{C}$ and $\mathrm{F}$ were found to be between the previous parameters. This finding attributed to the interact as strongly with nano composite films and starch or gelatin in the biopolymer film structure compared with water solubility of sago starch films, It was found that the solubility rate was of $17.4023 .12 \%$ while, Water vapor permeability $0.47-1.37 \mathrm{~g} / \mathrm{m}^{2}$. $24 \mathrm{hr}$ According to Alebooyeh et al., ${ }^{41} \mathrm{~Pa}$ tricia et al. ${ }^{20}$ High film elongation is always a desirable characteristic if the film is to be used for food applications Chen et al. ${ }^{42}$ Similar results were reported by Franciele et al. ${ }^{14}$ All main factors significantly affected the mechanical of the film as follows: a) the chitosan film had an $18 \%$ higher elongation than the chitosan/quinoa protein film) and In addition to incorporating the nanoparticles with the thymol, ${ }^{43-47}$ this reduced the chitosan film. ${ }^{6}$ 
Table 3 The thickness, mechanical properties and permeability of quinoa protein and starch nano particles to produce edible films

\begin{tabular}{|c|c|c|c|c|c|c|c|}
\hline Treatments & $\begin{array}{l}\text { Thickness } \\
\text { Um }\end{array}$ & $\begin{array}{l}\text { Tensile } \\
\text { strength } \\
(\mathrm{N} / \mathrm{M} 2)\end{array}$ & $\begin{array}{l}\text { Elongation } \\
\text { (\%) }\end{array}$ & $\begin{array}{l}\text { Oxygen (O2) } \\
\text { Permeability } \\
\mathrm{M}^{3} . \mathrm{M} / \mathrm{M}^{2} \times 10^{7} \text { day. } \\
\mathrm{mmHg}\end{array}$ & $\begin{array}{l}\mathrm{CO} 2 \\
\text { Permeability } \\
\mathrm{M}^{3} \cdot \mathrm{M} / \mathrm{M}^{2} \times 10^{-8} \\
\text { day.mmHg }\end{array}$ & $\begin{array}{l}\text { Water vapors } \\
\text { Permeability } \\
{\left[\mathrm{g} / \mathrm{m}^{2} .24 \mathrm{hr}\right]}\end{array}$ & $\begin{array}{l}\text { "\% Solubility" loss in } \\
\text { weight after dipping } \\
\text { in water and drying }\end{array}$ \\
\hline$A$ & 120 & 24.26 & 12.1 & 25.32 & 26.89 & 0.79 & 25.00 \\
\hline B & 70 & 95.23 & 40.1 & 5.54 & 11.32 & 3.67 & 9.16 \\
\hline C & 98 & 65.23 & 22.65 & 16.2 & 19.34 & 4.21 & 19.4 \\
\hline$D$ & 110 & 50 & 16.78 & 19.87 & 24.56 & 1.22 & 22.32 \\
\hline$E$ & 85 & 80.34 & 38.75 & 7.15 & 12.34 & 2.86 & 14.22 \\
\hline $\mathrm{F}$ & 94 & 72.33 & 26.43 & 9.23 & 8.1 & 5.42 & 16.43 \\
\hline
\end{tabular}

A= Film-forming based quinoa protein, glutaraldehyde, glycerol. B= Film-forming quinoa protein nanoparticles withaddition of (0.5/4.5\%) crude phenolic compounds extracts luria leaves/acetic acid glacial. C= Film-forming quinoa protein nanoparticles withaddition of (0.5/4.5\%) crude phenolic compounds extracts pomegranate Peels/acetic acid glacial. $D=$ Film-forming based quinoa starch,glycerol. E=Film-forming quinoa starch nanoparticles withaddition of $(0.5 / 4.5 \%)$ crude phenolic compounds extracts luria leaves/acetic acid glacial. F= Film-forming quinoa starch nanoparticles withaddition of ( $0.5 / 4.5 \%)$ crude phenolic compounds extracts pomegranate Peels/acetic acid glacial.

\section{Conclusion}

quinoa protein and starch nano particles-based coating and films supplemented with $(0.5 / 4.5 \%)$ crude phenolic compounds extract (as antioxidants) luria leaves or pomegranate Peel/acetic acid glacial were selected to the rheological, mechanical properties, permeability, partical size distribution, zeta potentioal emulsion, X-R diffraction(XRD) films and scanning electron microscopy. The best samples treatment were $\mathrm{B}(55.61 \mathrm{~nm}), \mathrm{E}(68.66 \mathrm{~nm}), \mathrm{F}(73.51 \mathrm{~nm})$ and $\mathrm{C}(84.13 \mathrm{~nm})$ film-forming quinoa protein and starch nano particles with the incorporation of $(0.5 / 4.5 \%)$ crude phenolic compounds extracts luria leaves or pomegranate Peels/acetic acid glacial.

\section{Acknowledgments}

None.

\section{Conflict of interest}

The author declares that there is no conflict of interest.

\section{References}

1. Letelier ME, Carmen RR, Sebastián SJ, et al. Surfactant and antioxidan properties of an extract from Chenopodium quinoa Willd seed coats. Journal of Cereal Science. 2016;53(2):239-243.

2. Ruales J, Nair BM. Nutritional quality of the protein in Chenopodium quinoa, Willd) quinoa seeds. Plant Foods Hum Nutr. 1992;42(1):1-11.

3. Food and Agriculture Organization. UnderutilizedAndean Food Crops. Rome. 1998.

4. Elsohaimy SA, Refaay TM, Zaytoun MAM. Physicochemical and functional properties of quinoa protein isolate. Annals of Agricultural Science. 2015;60(2):297-305.

5. Jafarizadeh MH, Osman A, Tan CP. Evaluation of effectiveness of three cellulose derivative-basededible coatings on changes of physico-chemical characteristics of 'Berangan' banana (Musa sapientum cv. Berangan) during storage at ambient conditions. J Nutr Health Food Eng. 2018;8(4):297-308

6. Caro N, Medina E, Díaz-Dosque M, et al. Novel active packaging based on films of chitosan - tripolyphosphate- thymol nanoparticales via ther- mal ink-jet printing . Food Hydrocolloids. 2016;52:520-532.

7. Dickinson E. Biopolymer-based particles as stabilizing agents for emulsions and foams. Food Hydrocolloids. 2016. p. 1-13.

8. Lazidis A, Almeida P, Spyropoulos F, et al. Microstructural design of aerated food systems by soft-solid materials. Food Hydrocolloids. 2017;73:110-119.

9. Phan-Xuan T, Durand D, Nicolai T, et al. Tuning the structure of protein particles and gels with calcium or sodium ions. Biomacromolecules. 2013;14(6):1980-1989.

10. Suisui J, Chenzhen L, Zhongjie H, et al. Evaluation of rheological behavior of starch nanocrystals by acid hydrolysis and starch nanoparticles by self-assembly: A comparative study. Food Hydrocolloids. 2016;52:914-922.

11. Mehdi JJ, Ashkan M, Mohamadsaeed Y. An attempt to cast light into starch nanocrystals preparation and cross-linking. Food Chemistry. 2013;141(3):1661-1666.

12. Livia BM, Monteiro ARG, Mikcha JMG, et al. Evaluation of Antioxidant and Antimicrobial Capacity of Pomegranate Peel Extract (Punica Granatuml.) Under Different Drying Temperatures. CHEMICAL ENGINEERING TRANSACTIONS. 2015;44:2283-9216.

13. Bushra S, Farooq A, Muhammad A. Effect of Extraction Solvent/Technique on the Antioxidant Activity of Selected Medicinal Plant Extracts. Molecules. 2009; 14:2167-2180.

14. Franciele Maria Pelissari, Margarita María Andrade-Mahecha, Paulo José do AS, et al. Comparative study on the properties of flour and starch films of plantain bananas (Musa paradisiaca). Food Hydrocolloids. 2013;30:68-690.

15. Zi Teng, Ruoyang Xu, Qin Wang. Betalactoglobulin-based encapsulating systems as emerging bioavailability enhancers for nutraceuticals: a review. RSC Advances. 2015;44

16. Shakeri S, Roghanian R, Emtiazi C, et al. Preparation of protein-loaded PLGA-PVP blend nanoparticles bynanoprecipitation method: entrapment, Initial burst and drug releasekinetic studies . Nanomed J. 2015;2(3):175-186.

17. Lohcharoenkal W, Wang L, Chen YC, et al. Proteinnanoparticles as drug delivery carriers for cancer therapy. J Biomed Biotechnol. 2014;2014(180549):1-15 
18. Galisteo Fand, Molina BJA. Systematic study on the preparation of BSA nanoparticles. Colloids Surf B. 2014;123:286-292.

19. Homa T, Mohaddeseh M. Inulinase Immobilization on Functionalized Magnetic Nano particles Prepared with Soy Protein Isolate Conjugated Bovine Serum Albumin for High Fructose Syrup Production. World Academy of Science, Engineering and Technology International Journal of Biotechnology and Bioengineering. International Scholarly and Scientific Research \& Innovation. 2017;11(7):546-553.

20. Araujo-Farroa PC, Podaderab G, Sobralb PJA, et al. Development of films based on quinoa (Chenopodium quinoa, Willdenow) starch. Carbohydrate Polymers. 2010;81(4):839-848.

21. Sun Q, Li G, Dai L, et al. Green preparation and characterization of waxy maize starch nanoparticles through enzymolysis andrecrystallization. Food Chemistry. 2014;162:223-228.

22. Saptarini NM, Herawati IE. The effect of acetic acid on total anthocyanins content and antioxidant activity of tamarillo (Solanum betaceum Cav). Journal of Pharmacy Research. 2018;12(3):398-401.

23. Olafsson G, Jagerstad M, Oste R, et al. Delamination of polyethylene and Aluminum Foil Layers of Laminated packaging Material by Acetic Acid. Journal of Food Science. 1993;58(1):215-219.

24. Lilian EA, Cristián T, Maria C. et al. Characterization of quinoa proteinechitosan blend edible films. Food Hydrocolloids. 2011; 25(5):879886 .

25. Sotelo-Boy ME, Valverde-Aguilar, Plascencia-Jatomea M, et al. Characterization Of Chitosan Nanoparticles Added With Essential Oils. In Vitro Effect On Pectobacterium Carotovorum. Caracterizacio' N De Nanoparti'Culas De Quitosano Adicionadas Con Aceites Esenciales. Efecto In Vitro En Pectobacterium Carotovorum. 2015;14(3):589-599.

26. Tien CL, Letendre M, Ispas-Szabo P, et al. Development of biodegradable films from whey proteins by cross-linking and entrapment in cellulose. J Agric Food Chem. 2000;48(11):5566-5575.

27. Food and Agriculture Organization. Assessment of theinternational year of quinoa 2013. Hundred and forty-ninthsession. CL 149/10. Italy: Rome; 2014

28. Hernandez-Mun P, Villalobos R, Chiralt A. Effect of cross-linking using aldehydes on properties of glutenin-rich films. Food Hydro. 2004;18(3):403.

29. Garcia MA, Martino MN. Zaritzky. Lipid addition to improve barrier properties of edible starch-based films and coating. J Food Sci. 2000. 65(6):941-947.

30. Wittmar A, Ruiz-Abad D, Ulbricht M. Dispersions of silica nanoparticlesin ionic liquids investigated with advanced rheology. Journal of Nanoparticle Research. 2012;4(2):651.

31. Z Teng, Luo Y, Wang T, et al. Development and Application of Nanoparticles Synthesized with Folic Acid Conjugated Soy Protein. J Agric Food Chem. 2013;61(10):2556-2564.

32. Hua Liu, Michael Eskin NA. Interactions of native and acetylated pea starch with yellow mustated mucilage, locust bean and gelatin. Food Hydrocolloids. 1998;12(1):37-41.
33. Hagenimana A, Ding X, Gu W. Steady state flow behaviours of extruded blend of rice flour and soy protein concentrate. Food Chemistry. 2007;101(1):241-247.

34. Ding P, Pacek AW, Frith WJ, et al. The effect of temperature and composition on the interfacial 278 tension and rheology of separated phase in gelatin/ pullulan mixtures. Food Hydrocolloids. 2005;19:567-577.

35. Dail RV, Steffe JF. Rheological characterization of cross-linked waxy maize starch solutions under low acid aseptic processing conditions using tube viscometry techniques. J Food Science. 1990;55(6):1660 1665 .

36. Jong YK, Seung TL. Preparation of nano-sized starch particles by complex formation with n-butanol. Carbohydrate Polymers. 2006;76(1):110-116.

37. Jie xiao, Yunqi Li, Qingrong Huang. Recent advances on food-grade particles stabilized pickering emulsion: Fabrication, characterization and research trends. Trends in Food Science \&Technology. 2006;55:4860 .

38. ASTM. Zeta Potential of Colloids in Water and Waste Water, In: ASTM Standard D, editors. American Society for Testing and Materials, 1985. p. $4187-4182$.

39. Valenzuela C, Abugoch L, Tapia C. Quinoa protein-chitosan-sunflower oil edible film: mechanical, barrier and structural properties. LWT e Food Science and Technology. 2013;50(2):531-537.

40. Sailaja A, Amareshwar P. Preparation of SA nanoparticles, by desolvation technique using acetone as desolving agent. International journal of pharmaceutical sciences \& nanotechnology. 2012;5(1):1647-1643.

41. Alebooyeh R, Mohammadi NA, Jokar M. The Effects of ZnOnanorodson the Characteristics of Sago Starch Biodegradable Films. Journal of Chemical Health Risks. 2012;2(4):13-16.

42. Chen H. Functional properties and applications of edible films made of milk proteins. J Dairy Sci. 1995;78(11):2563-2585.

43. ASTM Standard D, American Society for Testing and Materials, Zeta Potential of Colloids in Water and Waste Water, In: ASTM. 1985. p. 4187-4182.

44. Catarina Pinto R, Ronald J Neufeld, Antonio J Ribeiro, et al. Nan encapsulation I Methods for preparation of drug-loadedpolymeric nanoparticles. Nanomedicine. 2006;2(1):8-21.

45. Mirandaa M, Vega-Gálvezab A, Uribe E. Physico-chemical analysis, antioxidant capacity and vitamins of six ecotypes of chilean quinoa (Chenopodium quinoaWilld). Procedia Food Science. 2011;1:1439-1446.

46. Hernández-Muñoz P, López-Rubio A, Del-Valle V, et al. Mechanical and water barrier properties of glutenin films influenced by storage time. J Agric Food Chem. 2004;52(1):79-83.

47. Zi Teng. Food protein-based nanoparticles as bioavailability enhancing encapsulants. Dissertation submitted to the Faculty of the Graduate School of the University of Maryland, College Park, in partial fulfillment of the requirements for the degree of Doctor of Philosophy. 2015. 